Prophylaxis.

A disease like rheumatic fever, which certainly occurs chiefly in dry soils, appears to afford but little scope for pre. ventive measures. It would appear at first sight to strike at the root of the hygienic axiom that a dry soil is the most healthy. It is probable that a distinction must be carefally drawn between dryness of soil due to its drainage, to the removal of locks, mill-ponds, \&c. from the neighbouring streams, and dryness of soil due to a series of hot and dry seasons. The latter would be associated with a higher temperature of the soil than the former, and would undoubtedly have a different effect on the biological quality of the soil..$^{30}$

\section{A CASE OF SARCOMA OF THE BRAIN SUCCESSFULLY REMOVED BY OPERATION.}

BY GEORGE R. MURRAY, M.A., M.B. CAMB., M.R.C.P. LOND.,

EEATH PROFESSOR OF COMPARATIVE PATHOLOGY IN THE UNIVERSITY OF DUREAM; PATHOLOGIST TTO THE HOSPITAL FOR SICK CHIDDREN, NEWCASTLE-ON-TYNE ; AND

W. G. RICHARDSON, M.B.DURH., F.R.C.S. ENG, SURGICAI REGISTRAR, ROYAL INFTRMARY, NEWCASTLE-ON-TYNE.

THe following case is published as an example of the good results which may be obtained by the removal of a cerebral tamour, even when it has attained a considerable size.

The patient was a married man aged thirty-six years Before the commencement of the present illness he had always enjoyed good health, and was well able to do hard work. He had never had any severe illness or injury, nor could any history of syphilis be obtained. Soon after the beginning of Hebruary, 1894, and as far as can now be ascertained on the 11th of that month, he was suddenly seized with a slight attack of Jacksonian epilepsy. He stated that in this attack the left elbow was raised from the side, and that the forearm was pronated and supinated in the flexed position several times in rapid succession. The attack was limited to the left arm, and he was perfectly conscious all the time. Nine days later, on F'eb. 20th, he had a similar attack, again involving the left arm only, but accompanied by a tingling sensation, which was felt all over the left side of the head. Four days after this he had a third attack similar in all respects to the second. Since then he had had no general or localised convulsion. He did not notice any loss of power in the left arm immediately after these attacks. He continued at his work for another week, till one day he felt cold and was seized with nansea, which was followed by a severe attack of vomiting. The next day (March 4th) he found that he had lost some power in the left arm, and since then he had been unable to work. The left arm gradually became weaker till it finally was almost completely paralysed. About a fortnight after he left his work he felt that he was beginning to lose power in the left leg, but there had not been any convulsive seizure involving the leg. Attacks of vomiting occurred regularly two or three times a week. About the beginning of April he began to complain of an aching pain in the right temporal region. The symptoms all gradually became more marked up till the middle of May, when Dr. Murray first saw the patient in consultation with Dr. H. S. Baumgartner of Newcastle and Mr. Yoakley of Heaton. At that time the patient complained of headache on the right side and severe attacks of vomiting. There was paralysis of the left arm, with considerable loss of power in the left leg, so that he could only get about the house with difficulty by the help of a stick. There was wellmarked double optic neuritis, the neuritis being rather more adranced in the right eye than in the left. The symptoms pointed clearly to the presence of a cerebral tumour, which we concluded primarily involved the cortex of the middle third of the ascending frontal and ascending parietal convolntions, and was extending upwards towards the longitudinal fissure. It was determined to administer full doses of potassium iodide for a few weeks in the first place, and, if no improvement took place, to have the tumour removed. Fifteen grains of potassinm iodide were given three times a day.

30 We regret that exigencies of space have compelled us to omit paragraphs here and there of Dr. Newsholme's interesting lectures, tut though the points of disconnexion are here and there apparent the argument has not, we trust, suffered.-FD. I
Beyond a temporary diminution in the frequency of the attacks of vomiting no improvement took place, and the condition of the patient became worse, so that at the end of six weeks we decided that the tumour should be removed without any further delay.

Condition of the patient at the time of operation.-The patient complained of headache which was always confined to the right side of the head. The pain, however, appeared to shift from one part of this side of the head to another, and was sometimes felt in the temporal and at others in the occipital region. He also complained of feeling as if he had received a blow on the head in the right parietal region. He frequently heard noises in the head, which at one time sounded like an engine at work and at another like a bell ringing. He had severe and prolonged attacks of vomiting almost every other day. The speech was clear and the memory unimpaired. His temper had become irritable, but in all other respects his mental condition was unaffected. On tapping the right side of the head there was found to be a small tender area surrounding a point situated one inch from the middle line on a line drawn at right angles to it and passing down through the right external auditory meatus. The eyes were examined by Dr. Archibald Percival, who reported their condition to be as follows. Vision was nearly $\frac{B}{12}$ with either eye. The fields were normal. In each eye the colour sense was good and the colour field normal. Tuight sense was impaired slightly. There was pronounced optic neuritis in both eyes. Left disc : $\frac{2}{3} \mathrm{~mm}$. swelling. There was a small amount of hæmorrhage near the lower and onter margin of the disc. The vessels were partly obscured by the œedema in places. Right disc: the swelling was estimated at $1 \mathrm{~mm}$.; a few fine vitreous opacities were occasionally and with difficulty seen. the tension was the same in both eyes. Elevation and depression were good. Conjugate movements were rather jerky, ranging to the extreme right or the extreme left. The pupils acted, but not very briskly, to light and accommodation. The other cranial nerves were unaffected. The left arm was almost completely paralysed, as the patient was unable to raise the arm by means of the shoulder muscles, and the movement which he made in endeavouring to raise the arm was due to rotation of the scapula. In the sitting position, with the arm hanging down, he was unable to execute the slightest movement of the forearm, hand, or fingers. When he was lying on his back in bed with the arm at his side he was found to have still some slight power in the flexors and extensors of the elbow-joint. There was a slight amount of rigidity of the biceps and supinator longus muscles. There was scarcely any dimination in the size of the muscles of the left arm and forearm. The thenar and hypothenar eminences were rather soft and flattened owing to some wasting of the intrinsic muscles of the band; the interosseous spaces were more conspicuous than on the right. The triceps, the supinator longus, and the other muscles of the forearm were in a marked condition of myotatic irritability, and responded actively to mechanical stimulation. The patient could just walk across the room without support, but as a rule used a stick or supported himself by the furniture. The left leg dragged considerably as he walked; when sitting he could cross the left leg over the right knee. The power of flexion and extension of the left thigh was much less than on the right side. The extensor muscles of the left knee-joint were also less powerful than on the right, but the flexors were much weaker. $\mathrm{He}$ was unable to execute any movement of the foot or toes. Sensation to touch, pain, heat, and cold was unaffected. The muscular sense was lost for the left arm, as he was unable to tell the position of the limb unless he was aided by visual or sensory impulses. The knee-jerk was much exaggerated on the left it was also more active than usual on the right. Ankleclonus could be obtained on the left side, but not on the right. The superficial plantar reflex was exaggerated on the left. On pricking the dorsum of the left foot a reflex flexion of the foot took place, but only after an unusually long interval. The limbs of the right side were unaffected. Micturition and defæcation were carried out normally, and in all other respects the patient was healthy.

In this case the presence of headache, vomiting, and double optic neuritis associated with nnilateral paralysis clearly indicated that the diagnosis of a cerebral tumour was correct. The localised epileptic attacks affecting the left arm, followed by progressive loss of power of that arm, and later by loss of power in the left leg, showed that the tumour was situated in the right half of the brain, and that it primarily involved either the cortical motor centre for the 
arm or the fibres passing down from that centre in the internal capsule. As localised convulsion of the left arm was the first symptom of the tamour which appeared, we concluded that the tumour primarily involved the cortex. As the facial muscles were unaffected it appeared most probable that the tumour had first of all involved the middle third of the right ascending frontal and ascending parietal convolutions, and had subsequently extended upwards and inwards towards the longitudinal fissure, affecting either the cortical leg centre or the fibres passing down from it, but to a less extent. We agreed, therefore, that it would be advisable to expose the surface of the brain at a point corresponding to the junction of the apper and middle thirds of the fissure of Rolando.

Operation by Mr. RICHARDson.-Two days before the operation the head was shaved and washed with soft soap and then with tarpentine. The day before the head was treated in the same way. In the forenoon the right side of the bead was marked out with an aniline blue pencil with Reid's lines. A mark was made at the junction of the upper and middle thirds of the line corresponding to the fissure of Rulando. Tuis point was exactly on the part of the scalp which was tender to per-

FIG. 1.

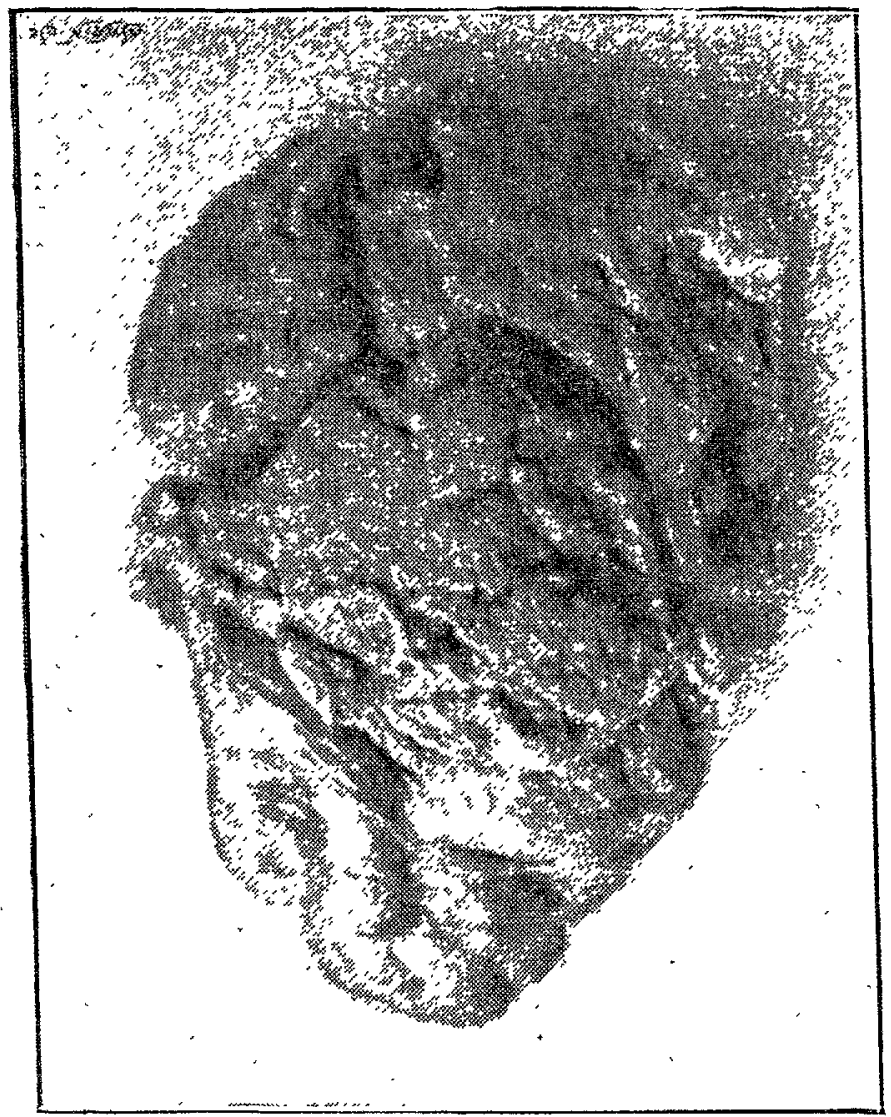

Upper surface of tumour (natural size).

cussion with the finger tip. In the evening the whole head was again washed with soft soap and then with turpentine, after which a dressing of lint soaked in a 1 in 1000 solution of corrosive sublimate was applied over the whole scalp and was left on until the time of operating. The operation was performed on July 1st, 1894, at 11 A.M. Immediately before the administration of chloroform a quarter of a grain of morphia was injected hypodermically. A horseshoe incision was made from a point two inches behind and above the right ear to a point two inches behind and above the external angular process of the right orbit, the convexity of the incision reaching to the sagittal suture. The scalp and periosteum were raised in one sheet, the vessels being caught in clip forceps. A one-inch trephine was applied at the point overlying the junction of the apper and middle thirds of the fissure of Rolando, and a crown of bone was removed. The same trephine was again applied a little above and in front of this hole and another crown was removed. The two trephine circles overlapped, forming one opening. On removing the crowns of bone the pulsations of the brain were observed. The dura mater was incised along the posterior and lower margins of the opening about a quarter of an inch from the edge of bone. On raising the dura mater the cranial contents bulged up and the lower and back parts of the exposed surface were seen to be brain, but the major part was tumour, which was easily distinguished from the adjacent brain substance by its uniform bluish tint. The opening in the skull was then enlarged, chiefly forwards and upwards, by cutting away the bone with punch forceps, the dura mater was divided until the whole surface of the tumour was exposed surrounded by brain except at the upper part where the tumour was attached to the dura mater. The exposed area of the tumour was about the size of a penny (the part which was seen is indicated as a circular patch in the engraving of the upper surface of the tumour). It was readily separable from the surrounding brain by a director, but it was then found that about half an inch from the surface the growth expanded in all directions. As the upper part of the tumour was attached to the dura mater this point was untouched until the body of the growth had been cleared. By enlarging the opening in the bone, by incising the dura mater when necessary, and by carefully working with a flat periosteal elevator, the tumour was lifted out of the brain and then only remained attached to the dura mater. It was not found necessary to damage the brain in any way. By working with the elevator on the denser new growth

FIG. 2.

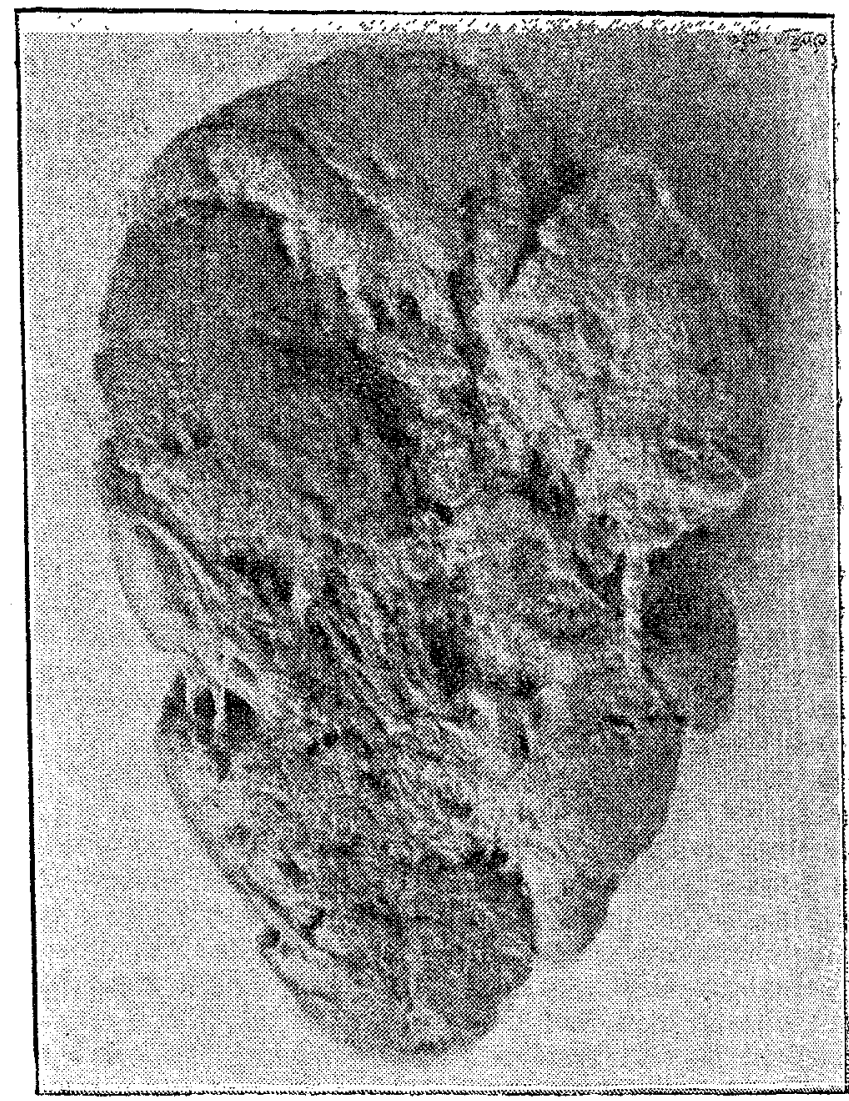

Under surface of tumour (natural size).

the elastic tumour came ont of its bed and through a comparatively small aperture in the surface of the brain. The cavity in which it had lain slowly closed as the tumour was removed. There was not much bleeding from the cavity, and what there was very soon ceased. One cortical vein was ligatured. The tumour was then taken away along with the dura mater, and in separating the latter a vein was cut across close to its point of entry into the longitudinal sinus. This vein was canght in clip forceps and ligatured with catgat. The shallow cavity now left was filled with corrosive sublimate ganze, the tail of which was bronght ont at the posterior part of the scalp wound. The scalp was sutured with silk and a dressing of corrosive sublimate gauze and wood-wool was applied. The operation lasted about an hour. The patient was returned to bed considerably collapsed, the pulse feeble, extremities cold, and general sweating. At 3 P.M. he was still unconscious. Respiration was 14 per minute; the pulse 100 per minute. The pupils were very small; conjunctival reflex returned. The extremities were warm. The patient moved his head. At 6 P.M. the patient regained conscionsness and felt comfortable. He vomited once or twice.

Except from the diploe there was very little bleeding. From the diploe more than a pint of blood was lost, and this 
was much the most serious contingency. During the the operation the brain was not handled, all the manipalations being on the tumour, the flat surface of the periosteal elevator alone coming in contact with the brain. The instruments and sponges were kept in a 1 in 40 carbolic lotion. There was very little sponging, and all things were kept as dry as possible. There was never any free lotion in the wound. The dura mater having been removed on account of its attachment to the tumour, the pieces of bone were not replaced; a permanent opening is thus left in the skull, measuring two inches and three-quarters by two inches and a quarter.

Description of the tumour. - The appearance presented by the trmour is well shown in the two plates, which represent the actaal size of the growth. It measured 3 in. in length, $2 \mathrm{in}$, in breadth, and $1 \frac{1}{4}$ in. in depth. On microscopical examination the tumour proved to be a sarcoma.

After.progress.-The progress of the patient after operation was in every way most satisfactory. The temperature only once reached $100^{\circ}$ forty-eight hours after the operation ; on four other occasions only did it rise above $99^{\circ}$. After the first forty-eight hours the pulse ranged between 72 and 88 . As an immediate result of the operation the vomiting and the noises in the head ceased, the pain in the head was relieved, and the irritability of temper disappeared. With the exception of the night after the operation, when sleep was broken, the patient slept about eight hours each night. F or the first twelve days the wound was dressed daily on account of the large amount of cerebro-spinal fluid which saturated the dressings. On the third day the gauze plug was removed. This was not accompanied by any hæmorrhage, but a small fusiform piece of brain substance, one inch in length and a quarter of an inch in diameter, came away with it. On the fourth day the entire scalp and face were very much swollen and cedematous, especially on the left side, on which the patient had been lying. This swelling, which continued daring the fifth day and gradually subsided on the sixth without having produced any ill-effects, appeared to be entirely due to extravasation of cerebro-spinal fluid into the sub. cataneous tissues. The wound anited by first intention with the exception of the small opening, through which the cerebrospinal lluid continued to leak for about three weeks. There was profuse diaresis during the whole of the third week. For five days six pints of urine were passed in the twenty-four hours. On the sixth and seventh days of the third week nine and a half pints of nrine were passed. The urine was clear and did not contain either sugar or albumen. The muscles of the left arm and leg rapidly regained power in the following order On Jaly 3rd there was already some increase in the power of the extensors and flexors of the forearm. The patient could extend and invert the left foot and flex the great toe to a very slight extent. On waking on the morning of the 7th the patient stretched himself, and the nurse noticed that he stretched out the left arm as well as the right, and also extended the fingers of the left hand, movements which he was quite unable to execute voluntarily while fully a wake. 0 a the 9 ch the power of flexion and inversion of the left foot and of flexion of the great toe had increased. The associated morements of the left arm occurred each morning when the patient stretched on waking. On the 12th he got out of bed and walked across the room. In doing so he was able to carry the left leg forward more strongly than before the operation. $0 n$ the 17 th the patient could abduct and raise the left arm a little. In the erect position he could fally flex the elbow, and the rigidity of the biceps had diminished. There was a distinct increase in power in both the Hexors and extensors of the hip-joint and of the knee-joint. When lying on his back he conld flex and invert his foot and flex the toes to a slight extent. In walking the left foot was no longer dragged, but was carried forward with a semicircular sweep, and when planted showed a tendency to assume a position of slight equino-varus, with the toes spread out. The reflexes had not changed in character since the operation. On the 20th the fingers were voluntarily flexed for the first time. On the $28 \mathrm{th}$ there was considerable power of flexion in the left thumb and index finger. He could walk about the house without any support. On the 30th the thumb and all the fingers of the left hand could be feebly extended. On Aug. 1st the left wrist conld be slightly extended. On the 10th the wrist and fingers could be fully flexed and extended and a stick could be grasped in the left hand. The optic neuritis had very much diminished since the removal of the tamour. On the 13th the hand could be pronated and supinated. On Sept. 3rd all the muscles of the left upper limb could be made to contract voluntarily and all movements executed, though much less strongly than on the right. He could walk two miles with the help of a stick. On Oct. 10th the patient felt well. There was no headache, pain, or noise in the head. He slept and ate well, and his general health was excellent. He could walk as many as five miles with the help of a stick. He could use the left arm for many purposes. He could touch the back of his head, take off his cap, and use a fork with the left hand. There was, however, some rigidity of the muscles of the arm. The muscular sense was still deficient, but not to such an extent as it was three months before. He still walked with a limp, but could advance the left foot fairly well, and there was less circumduction than there had been. The reflexes remained just as they were before the operation. Only slight traces of the optic neuritis could now be seen. There was slight bulging of the scalp over the site of the tumour, but now that the hair had grown ag in this showed but little.

Remarks.-The improvement which had taken place in the condition of the patient within three months of the removal of the tumour was very considerable. From being unable to lift the arm or walk further than across the room, the patient could use the arm for many purposes and walk five miles without fatigue. The headache, vomiting, and noises in the head were removed at once by the operation. The optic neuritis steadily subsided after it. The after-progress was as straightforward as it usually is after quite a minor operation. The treatment was carried out in an ordinary bedronm, and, except at the operation itself, without the aid of skilled nursing. The improvement has been fully maintained, and the patient is now (March 5th, 1895) in excellent general health. He says that he can walk "any distance." The grasp of the hand is as strong on the left as on the right side. Newcastle-on-Tyne.

\section{CASE OF A GIRL SAID TO HAVE BEEN MIRACULOUSLY CURED OF PARALYSIS AT ST. WINEERIDE'S WELL, NORTH WALES.}

By THOMAS OLIVER, M.D.GLASG., F.R.C.P. LOND, PHISICIAN TO THE ROYAT INFIRMARY, NEWCASTLE-UPON-TYNE.

The publicity given in the daily and weekly press to the. "miraculous cures" that have been effected at Holywell, the pictorial representations of St. Winefride's Well in several of the illustrated papers, and the fact that for several weeks past I have been the recipient of letters of inquiry from various parts of England, most of them hitherto unanswered, must be my excuse for placing in THE LANCET the medical facts of a case already encircled by the halo of romance and round which is being thrown an air of mystery. For some time past Holywell has been the resort of an increasing number of invalids, each hoping by immersion to be suddenly relieved of his or her infirmity. If the stories of the " miraculous cures" thereat accomplished can be accredited the Well of St. Winefride bids fair to rival Lourdes, whose grotto is now world-known, and of which and the hordes of human wrecks that besiege it Zola has given us a marvellously realistic delineation. Holywell claims its cures not less traly' though less pretentiously than the little French town that: nestles in the Pyrenees ; and, as one of the recent cures that. have taken place at Holywell concerns a patient who was formerly under my care in the Newcastle Infirmary, I shall briefly state the history of her case before her visit to the Well of St. Winefride and since her retarn from it, simply introducing here and there relevant facts that have been supplied to me by the patient or the mother, who accom=. panied her to North Wales.

The patient, a young woman aged seventeen years, was admitted to the Royal Infirmary, Newcastle-upon-Tyne, on April 28th, 1894, complaining of curvature of the spine, pain in the legs and of difficulty in walking, pains in the head, and occasional dimness of sight. Her father died fifteen years ago from typhoid fever; her mother is still living and healthy. She has five brothers and one sister, all of whom are rather delicate. At the age of eleven patient left school, but owing to ill-health did nothing until 